\title{
Betamethasone causes intergenerational reproductive impairment in male rats
}

\author{
Cibele dos Santos Borges ${ }^{a}, *$, Taina Louise Pacheco ${ }^{a}$, Katiussia Pinho da Silva ${ }^{b}$, \\ Fábio Henrique Fernandes ${ }^{c}$, Mary Gregory ${ }^{\mathrm{d}}$, André Sampaio Pupo ${ }^{\mathrm{b}}$, \\ Daisy Maria F. Salvadori ${ }^{\mathrm{c}}$, Daniel G. Cyr ${ }^{\mathrm{d}}$, Wilma De G. Kempinas ${ }^{\mathrm{a}}$ \\ a Department of Morphology, Institute of Biosciences of Botucatu, UNESP - São Paulo State University, Distrito de Rubião Junior s/ $n^{\circ}$, Botucatu, SP \\ 18618-689, Brazil \\ ${ }^{\mathrm{b}}$ Department of Pharmacology, Institute of Biosciences of Botucatu, UNESP - São Paulo State University, Distrito de Rubião Junior s/ ${ }^{\circ}$, Botucatu, SP \\ 18618-689, Brazil \\ ${ }^{c}$ Department of Pathology, Botucatu Medical School, UNESP - São Paulo State University, Distrito de Rubião Junior s/n ${ }^{\circ}, 18618-689$ Botucatu, SP, Brazil \\ d Laboratory for Reproductive Toxicology, INRS-Institut Armand-Frappier, University of Quebec, 531 Boulevard des Prairies, Laval, Québec H7 V 1 B7, Canada
}

\section{A R T I C L E I N F O}

\section{Article history:}

Received 19 October 2016

Received in revised form 27 March 2017

Accepted 26 April 2017

Available online 10 May 2017

\section{Keywords:}

Betamethasone intergenerational effects

Puberty onset

Sperm quality

Fertility

Seminal vesicle contractility

\begin{abstract}
A B S T R A C T
Prenatal betamethasone (BM) exposure in rats negatively impacts sperm quality and male fertility. Studies have shown that BM can cause multi-generational effects on the pituitary-adrenal-axis of rats. The objective of this study was to assess the reproductive development and fertility of male rats (F2) whose fathers (F1) were exposed to BM $(0.1 \mathrm{mg} / \mathrm{kg})$ on gestational days $12,13,18$ and 19 . In F2 rats, there was a significant reduction in body weights of the BM-treated group at PND 1 as well as delayed onset of puberty, and decreases in FSH levels, Leydig cell volume, sperm number and motility, seminal vesicle contractility and ejaculated volume. Furthermore, increased serum LH levels, sperm DNA damage and abnormal morphology were observed, resulting in reduced fertility. In conclusion, prenatal BM-treatment leads to intergenerational long-term reproductive impairment in male rats, raising concern regarding the widespread use of BM in preterm births.
\end{abstract}

(c) 2017 Elsevier Inc. All rights reserved

\section{Introduction}

Increased levels of glucocorticoids are necessary in the later stages of pregnancy to promote the maturation of several organs, including the lungs [1]. For pregnant women at risk of preterm birth, prenatal synthetic glucocorticoids, especially betamethasone (BM), is administered to decrease the incidence of neonatal mortality due to respiratory distress syndrome $[2,3]$.

Thus, glucocorticoids play an important role in promoting fetal lung maturation and reducing neonatal death, and because of this, have a fundamental role in determining fetal programming [4,5]. Animal studies have demonstrated that fetal exposure to elevated doses of synthetic glucocorticoids at the end of the gestational period results in behavioral, endocrine, and metabolic abnormalities [6].

Our laboratory has previously demonstrated that, in utero, BMtreatment during two critical periods of development (days 12 and

\footnotetext{
* Corresponding author.

E-mail address: cibelesantosborges@gmail.com (C.d.S. Borges).
}

13 , corresponding to the period of germ cell migration and proliferation, and days 18 and 19, when testosterone levels increase) resulted in several important alterations to male sexual development, sperm quality and fertility. Furthermore, the treatment altered the normal pattern of Sertoli and germ cell organization in the testis of the rat, suggesting that reproductive programming may be dramatically altered by BM-treatment [7-10].

In the past several years, studies have attempted to demonstrate the influence of intra-uterine treatment of glucocorticoids using a multi-generational approach [5,6]. Drake et al. [11,12] observed changes in body weights, as well as in the expression of growth factors and hepatic proteins of rat fetuses exposed to dexamethasone during intrauterine development in both the first and second generation. Furthermore, prenatal exposure to BM resulted in trans-generational changes to the hypothalamic-pituitary-adrenal axis, resulting in altered ACTH (adrenocorticotropic hormone) secretion and changes in both glucocorticoid and mineralocorticoid receptors in the adrenal gland [13]. Thus, knowing the effects on the male reproductive tract in first generation $[7,8]$, the present study investigated the possible inter-generational reproductive impact of BM on sperm quality and fertility of second generation males 
whose fathers were exposed at critical stages of in utero sexual differentiation.

\section{Materials and methods}

\subsection{Animals}

Male (90 days old/300-350 g) and female (90 days old/225-230g) Wistar rats were obtained from the Multidisciplinary Center for Biological Investigation, State University of Campinas, and maintained under controlled conditions $\left(25^{\circ} \mathrm{C}\right.$, $30 \%$ air humidity, 12/12-h light/dark cycle) with food and water available ad libitum.

The experimental procedures used in this study were approved by the local Ethics Committee for the Use of Experimental Animals under protocol number 451-CEEA in accordance with the Guide for the Care and Use of Laboratory Animals (National Institutes of Health).

\subsection{Experimental design}

One nulliparous female rat was mated with a male during the dark cycle of the photoperiod (Fig. 1). The detection of sperm in the vaginal smear of the female rat in estrus was considered as gestational day (GD) 1. Pregnant and lactating rats were maintained in individual cages.

Pregnant female rats were randomly allocated into two experimental groups: control (saline vehicle, $\mathrm{n}=11$ ) and $\mathrm{BM}$ treated $(0.1 \mathrm{mg} / \mathrm{kg}$; Betamethasone 21-phosphate disodium; Sigma-Aldrich, St Louis, MO, diluted in vehicle, $\mathrm{n}=13$ ). Rats received an intramuscular injection of vehicle $(0.1 \mathrm{ml} / \mathrm{kg})$ or BM on days $12,13,18$ and 19 of pregnancy. Days 12 and 13 correspond to the period of germ cell migration and proliferation while days 18 and 19 are when gestational testosterone levels increase. After birth, several analyses were performed on pups, as described previously by Borges et al. [7,8]. One male per litter was kept until post-natal day (PND) 90 ( $n=11 /$ group), and was mated with a non-treated female to generate the second generation. The detection of sperm in vaginal smears was considered as GD 1. Dam gestation body weight and body weight gain were monitored. After birth, on PND 1, the number of pups per litter (F2) and sex ratio was calculated and, the pups were randomly selected in order to have 8 pups ( 4 male and 4 female littermates) per lactating female in order to maintain a similar pattern of food distribution between pups. Rats were weaned at PND 21 and housed in separate cages ( $n=4$ males per cage).

\subsection{Study 1: initial development and sperm quality}

\subsubsection{Anogenital distance and external examination at puberty}

Rat pups (F2) were weighed and the anogenital distance was measured at PND 1 in four male rats per litter ( $n=11$ per group).
The onset of puberty was determined by manual retraction of the prepuce in the same pups (four males/litter) [14].

\subsubsection{Organ weights}

One male rat per litter on PND 45 ( $n=10$ /group) and PND 110 ( $n=10$ /group) were weighed and euthanized. Blood was then collected (9:00 and 11:30 AM) and the right testis, seminal vesicle (full and empty, without the coagulating gland), and ventral prostate were dissected and weighed. The left testes were fixed for histology and immunohistochemistry. For animals at PND 110, the parenchyma of right testis was obtained by cutting out the albuginea and removing the testicular fluid by centrifugation (3000 rpm) for $30 \mathrm{~min}$ at $4{ }^{\circ} \mathrm{C}$ and frozen at $-20^{\circ} \mathrm{C}$ for determining sperm counts. The right cauda epididymidis was used for sperm collection for intrauterine artificial insemination and sperm quality parameters. The remaining tissue was frozen and used for measuring sperm counts, as was the caput/corpus epididymidis.

\subsubsection{Serum hormonal levels}

Blood samples from animals described above, on PND 45 and 110 ( $n=10 /$ group) were allowed to coagulate and the serum obtained by centrifugation $(2400 \mathrm{rpm})$ for $20 \mathrm{~min}$ at $4{ }^{\circ} \mathrm{C}$. Serum samples were subsequently stored at $-20^{\circ} \mathrm{C}$. Serum testosterone, FSH and LH levels were determined by radioimmunoassay. Testosterone levels (serum and intratesticular) were measured using the Coat-A-Count ${ }^{\circledR}$ assay (Diagnostics Products Corporation, Los Angeles, USA), while LH and FSH levels were measured using specific kits supplied by the National Institute of Arthritis, Diabetes and Kidney Diseases (NIADDK). Intra-assay variabilities were $3.4 \%$ for $\mathrm{LH}, 2.8 \%$ for $\mathrm{FSH}$, and $4 \%$ for testosterone. Using the hormone values, Leydig cell function was determined by measuring intratesticular testosterone levels (ITT)/LH levels (IT ratio) as described previously [15].

\subsubsection{Fertility assessment by in utero artificial insemination}

Rats (F2) euthanized on PND 110 ( $n=10 /$ group) were used for fertility assessment using in utero artificial insemination as described by Borges et al. [8]. Briefly, females in proestrus were paired with sexually experienced vasectomized males for $1 \mathrm{~h}$. Receptive females were selected for the insemination procedure. Sperm were released from the right proximal epididymal cauda and a volume containing $5 \times 10^{6}$ sperm was injected into each uterine horn. One female was inseminated per male.

Twenty days later, the females were euthanized to evaluate fertility. After collection of the uterus and ovaries, the number of corpora lutea, implanted fetuses, and reabsorption sites were recorded.

\subsubsection{Sperm motility}

Sperm motility was evaluated in the same sperm sample used for artificial insemination [7]. An aliquot of $10 \mu \mathrm{l}$ of sperm suspension was immediately transferred to a Makler chamber and

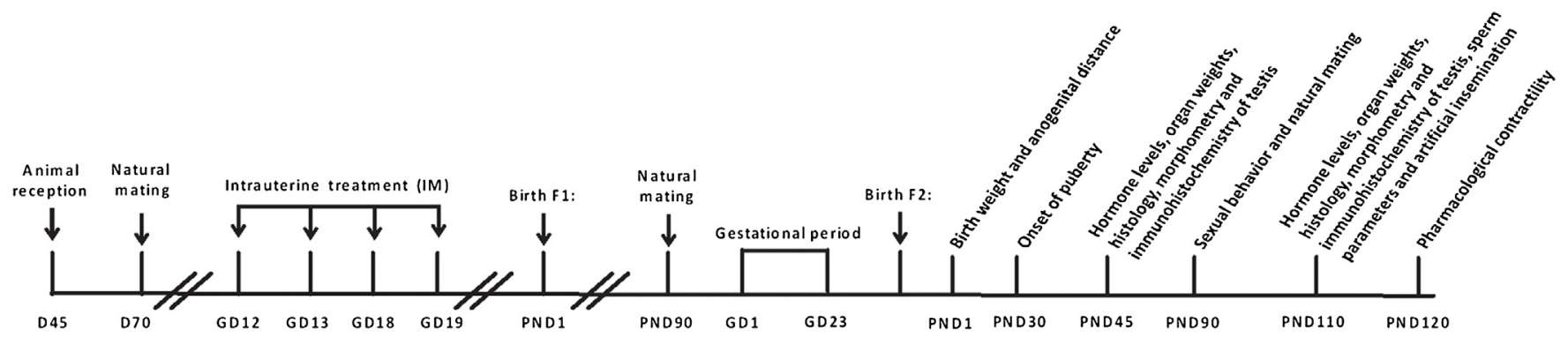

Fig. 1. Experimental design of animals whose fathers were exposed to vehicle (controls) or BM during the intrauterine development. 
maintained at $34^{\circ} \mathrm{C}$. Using a phase-contrast microscope (400× magnification), 100 sperm were counted and classified as Type A (mobile with progressive movement), Type B (mobile without progressive movement), and Type C (immobile).

\subsubsection{Sperm morphology}

An aliquot of $100 \mu \mathrm{l}$ of the sperm suspension from the artificial insemination was added to $900 \mu \mathrm{l}$ of formol saline $(810 \mu \mathrm{l}$ saline $+90 \mu \mathrm{l}$ formol). To analyze sperm morphology, smears were prepared on histological slides that were left to dry for $90 \mathrm{~min}$ and 200 spermatozoa per animal were analyzed under a phase-contrast microscope (400× magnification). Morphological abnormalities were classified into two general categories: head morphology (without characteristic curvature, pin or isolated head) and tail morphology (broken or rolled into a spiral) [16]. Sperm were also classified as to the presence or absence of the cytoplasmic droplet.

\subsubsection{Sperm counts and sperm transit time}

Homogenization-resistant testicular spermatids (stage 19 of spermiogenesis) were counted as described previously [8]. Briefly, testes ( $n=10 /$ group) were decapsulated, weighed, and homogenized in $5 \mathrm{ml}$ of $\mathrm{NaCl} 0.9 \%$ containing Triton X 100 0.5\%, followed by sonication for $1 \mathrm{~min}$. After a 10 -fold dilution, one sample was transferred to Neubauer chambers ( 4 fields per animal), and mature spermatids were counted. To calculate the daily sperm production (DSP), the number of spermatids at stage 19 was divided by 6.1 , which is the number of days of the seminiferous cycle during which these spermatids are present in the seminiferous epithelium [17]. The relative DSP was also obtained by dividing the daily sperm production by testis weight. The caput/corpus and cauda epididymidis were cut into small fragments with scissors and homogenized. Sperm were counted as described for the testis. The sperm reservoir in the cauda region of the epididymis was calculated by combining the number of cells in the sperm suspension and the sperm count in the homogenized tissue [7]. The sperm transit time through the epididymis was determined by dividing the number of sperm in each region of the epididymis by the DSP [17].

\subsubsection{Sperm DNA fragmentation (comet assay)}

Five F2 rats per experimental group (one per litter) were euthanized at PND 120. Sperm DNA fragmentation was evaluated by the comet assay as previously described [18] with the following modifications: frozen sperm samples from right cauda epididymides were thawed and diluted in low melting point agarose $(0.5 \%$ at $37^{\circ} \mathrm{C}$; LGC Laboratories, Sao Paulo, Brazil), at a concentration of $10^{6}$ cells $/ \mathrm{mL}$. An aliquot $(75 \mu \mathrm{l})$ of the solution was placed on pre-coated slides with $1 \%$ normal melting point agarose (LGC Laboratories, Middlesex, UK). The slide was first immersed in lysis buffer (100 mM Na 2 -EDTA, $10 \mathrm{mM}$ TrisHCl, 2,5 M NaCl, pH 11.0) containing $40 \mathrm{mM} \mathrm{DTT}$ and $2 \%$ Triton $\mathrm{X}-100$ for $1 \mathrm{~h}$ at $4{ }^{\circ} \mathrm{C}$ and subsequently in lysis buffer containing proteinase $\mathrm{K}(0.1 \mathrm{mg} / \mathrm{ml})$, for $2.5 \mathrm{~h}$ at $37^{\circ} \mathrm{C}$. The DNA was fractionated by alkaline electrophoresis $(300 \mathrm{mM}$ $\mathrm{NaOH}, 1 \mathrm{mM}$ Na2 EDTA, pH 13.0) at $3 \mathrm{~V} / \mathrm{cm}$ and $270 \mathrm{mAmps}$ for 45 mins. Finally, the slides were washing with water, fixed in absolute ethanol, air dried and stored in the dark until analysis. For microscopy, the slides were stained with SYBR $^{\circledR}$ Gold $(1: 10,000$; Invitrogen, Waltham, MA) and analyzed using the Comet Assay IV software (Comet Assay IV, Perceptive Instruments, Wiltshire, UK). DNA damage was measured by analyzing the tail intensity (\% of migrated DNA). A total of 50 cells were analyzed per slide ( 2 slides/animal).

\subsubsection{Histological analyses}

Left testes were fixed by immersion in Bouin's fixative, dehydrated, and embedded in Paraplast Plus ${ }^{\circledR}$ (P3683, Sigma-Aldrich). Tissues ( $n=5 /$ group) were sectioned $(5 \mu \mathrm{m})$, mounted on glass slides and stained with hematoxylin and eosin (HE) to evaluate testicular morphology. Sections destined for immunohistochemistry were mounted on silanized glass slides and stored at room temperature. Histopathology was analyzed in a blind assay using a Zeiss microscope (A1-Axio model) mounted with a digital camera and analysis software (ZeissAxio Vision, version 4.7.2). The histological analyses were performed as described previously [7]. Briefly, three non-serial testicular sections were taken for each animal in order to evaluate 100 seminiferous tubules. The interstitium, peritubular myoid cells and Leydig cells were also examined [19].

The diameter of the seminiferous tubules (stage IX of spermatogenesis) and thickness of germinal epithelium were evaluated in 10 sections of seminiferous tubules per animal. In order to evaluate the degree of maturation of the seminiferous epithelium, 100 cross-sections of seminiferous tubules per animal were randomly evaluated by assigning values according to the abundance of mature germ cells in the epithelium [20]. The following scale was used: category 1 (I): young spermatids with rounded nucleus (stages 1-8 of the cycle of the seminiferous epithelium); category 2 (II): spermatids in maturation phase, with ovoid or elongated nucleus (stages 9-14); category 3 (III): spermatids in maturation phase, with elongated nucleus (stages 15-18); category 4 (IV): mature spermatids (stage 19) in small numbers; category $5(\mathrm{~V})$ : mature spermatids (stage 19) in average numbers; category 6 (VI): mature spermatids (stage 19) in high abundance. Each symbol represents the number of tubules in the particular category. The "average category" was determined using the following mathematical formula: Average category $=[(\mathrm{I} \times 1)+(\mathrm{II} \times 2)+(\mathrm{III} \times 3)+(\mathrm{IV} \times 4)+(\mathrm{V} \times 5)+(\mathrm{VI} \times 6)] / 100$.

In order to evaluate the dynamics of spermatogenesis, the relative frequency of stages was estimated: I-VI (two generations of spermatids), VII-VIII (mature spermatids), IX-XIII (only one generation of spermatids), XIV (secondary spermatocyte) in 100 cross-sections of seminiferous tubules per animal. The relative frequency of stages estimates the rate or duration of spermatogenic process [21].

Furthermore, the number of Sertoli cell nuclei and the volume of Leydig cells were also determined. Sertoli cell nuclei were determined in histological sections from 20 seminiferous tubules per rat testis at stage VII of spermatogenesis. The nuclear volume of Leydig cells was measured by randomly selecting 50 circular or elliptical cells, their diameters (D) were measured, and the volume obtained using the formula: $\mathrm{V}=[\mathrm{D} \times \pi\} / 6[22]$.

\subsubsection{Immunohistochemistry for $c x 43$ and PCNA in the testis}

Histological sections were deparaffinized and hydrated in graded ethanol and washed in TBST (Tris-Buffered Saline, 0.1\% Tween-20). Sections were then subjected to antigen retrieval in citrate buffer $(0.01 \mathrm{M}, \mathrm{pH} 6.0)$ and heated in a microwave at $70 \%$ power for $10 \mathrm{~min}$. Slides were washed in $\mathrm{ddH}_{2} \mathrm{O}$, followed by hydrogen peroxide ( $3 \%$ ) for $15 \mathrm{~min}$, tap water ( $5 \mathrm{~min}$ ), and then incubated in blocking solution (TBST, 5\% BSA) for $1 \mathrm{~h}$ at $37^{\circ} \mathrm{C}$ in a humidified chamber. Sections were then incubated overnight with primary antisera as follows: anti-Cx43 (0.625 $\mu \mathrm{g} / \mathrm{ml}, \mathrm{C}-6219$; Sigma-Aldrich); or anti-PCNA ( $4 \mu \mathrm{g} / \mathrm{ml}$, SC-56/PC-10; Santa Cruz Biotechnology). Sections were then washed 3 times in TBST and incubated with the appropriate secondary antibody for $1 \mathrm{hr}$ at $37{ }^{\circ} \mathrm{C}$ (for $\mathrm{Cx} 43: 1 \mu \mathrm{g} / \mathrm{ml}$ goat anti-rabbit HRP, Abcam; for PCNA: $1.6 \mu \mathrm{g} / \mathrm{ml}$ goat anti-mouse HRP; Santa Cruz Biotechnology). Sections were subsequently washed with TBST and incubated with diaminobenzidine (DAB) $(0.5 \mathrm{mg} / \mathrm{ml}$, Sigma-Aldrich) for $15 \mathrm{~min}$, rinsed in tap water and counterstained with methylene blue for $5 \mathrm{~min}$. Negative control sections did not receive primary antibody. 


\subsection{Study 2: sexual behavior and natural mating}

\subsubsection{Evaluation of male sexual behavior}

At PND 90, one F2 male per litter ( $n=11$ /group) was placed in a cage alone for $5 \mathrm{~min}$ prior to the introduction of a sexually receptive female (in estrous phase determined by previous vaginal smears). Two observers watched the paired animals and manually registered the sexual behavior using a digital timer during the dark cycle of the photoperiod. Males that did not mount the female within the first 10 min were considered sexually inactive. Male sexual behavior was evaluated for 40 min starting from the first mount, and included the following parameters: latency to the first mount; latency to the first intromission; latency to the first ejaculation; number of intromissions until the first ejaculation; latency of the first post-ejaculatory intromission; number of postejaculatory intromissions; and total number of ejaculations. After sexual behavior, the female rats were kept with the same male for $3 \mathrm{~h}$ following which the male and female were removed and ejaculatory plugs were collected, counted and weighed. The means of the plug weights were expressed as the total plug weight per number of collected plugs.

\subsubsection{Fertility evaluation after natural mating}

The female rats used for sexual behavior were allocated in individual cages and vaginal smears were collected to confirm whether or not insemination occurred. Females naturally inseminated by rats from the control and treated groups were euthanized 20 days after mating to assess male fertility. A median laparotomy was done and the uterus and ovaries were collected. The parameters observed were the same as those described in Section 2.3.4 [8].

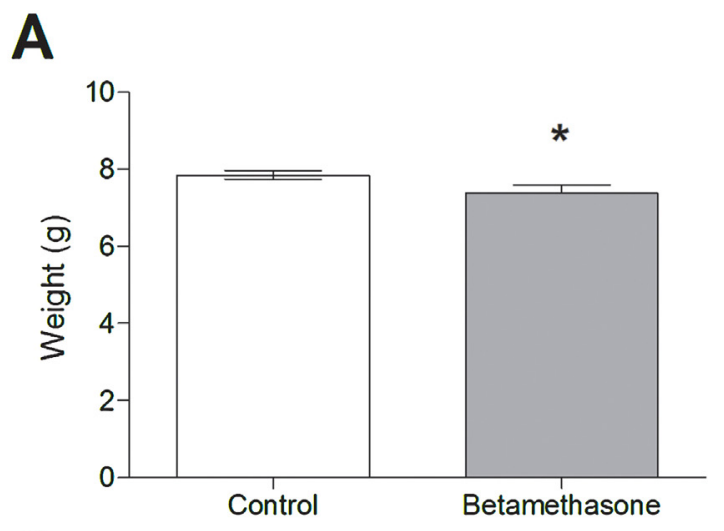

C

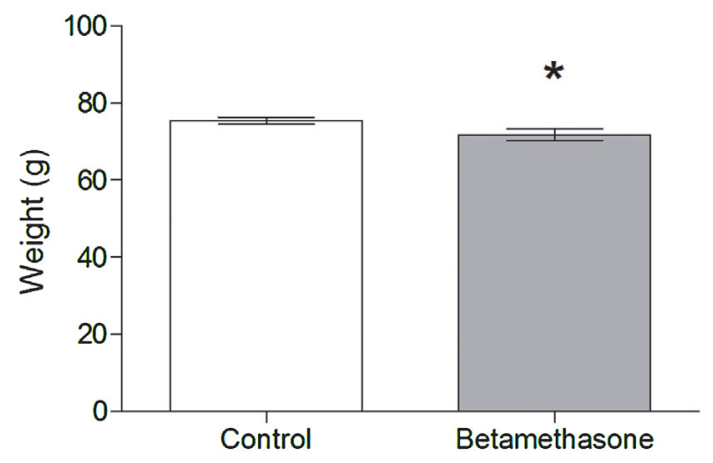

\subsection{Study 3-contractility of isolated seminal vesicle}

Five F2 rats per experimental group (one per litter) were weighed and euthanized at PND 120. A lobule of seminal vesicle was prepared for the in vitro tension recording as described below [23]. Tissues were mounted in $10 \mathrm{ml}$ organ baths in a modified Tyrode's solution at $30^{\circ} \mathrm{C}$ under $9.8 \mathrm{mN}$ (milliNewtons) resting tension and allowed to equilibrate for $30 \mathrm{~min}$. After the resting period, tissues were repeatedly challenged with $80 \mathrm{mM} \mathrm{KCl}$ every 30 mins until two reproducible contractions were obtained. Cumulative concentration-response curves to norepinephrine (NE, $10^{-8} \mathrm{M}-10^{-4} \mathrm{M}$ ) and carbachol (CCh, $10^{-8} \mathrm{M}-3.10^{-4} \mathrm{M}$ ) were obtained at $30 \mathrm{~min}$ intervals. The maximal tension developed (Emax,) and the potency to $\mathrm{NE}$ and $\mathrm{CCh}$ in developing tension (pEC50, the -log of agonist concentration inducing 50\% of Emax) were evaluated.

\subsection{Statistical analysis}

Data are presented as mean \pm standard error of mean (SEM) or median and interquartile range. A Studentís $t$-test was used for comparison of parametric variables. Non-parametric data were compared using a Mann-Whitney test. Differences were considered significant when $\mathrm{p} \leq 0.05$. Statistical analyses were performed using the GraphPad InStat software (version 5; La Jolla, CA).

\section{Results}

\subsection{Study 1: initial development and sperm quality}

Body weights and weight gain of dams during pregnancy were similar between groups (data not showed). At PND 1, the number of pups per group (control: $10.55 \pm 0.49$ and BM: $11.18 \pm 0.42$ )

B

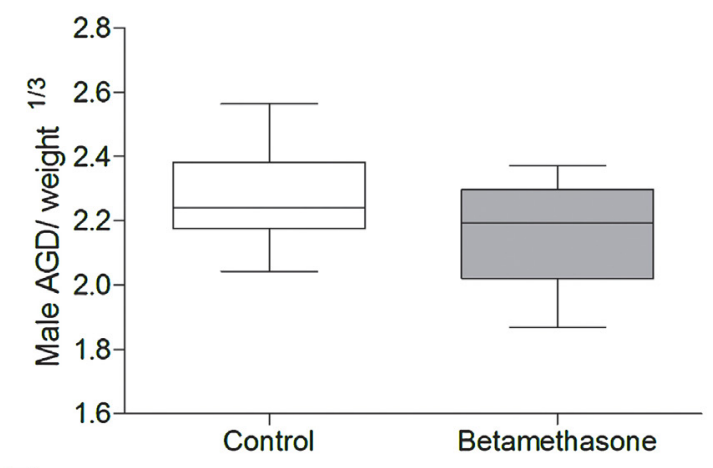

D

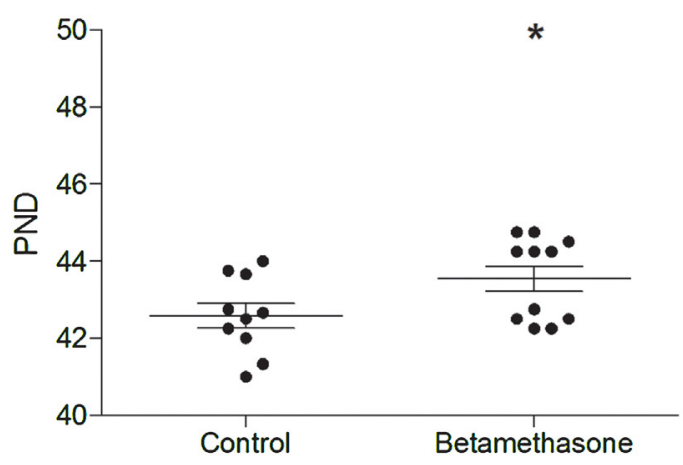

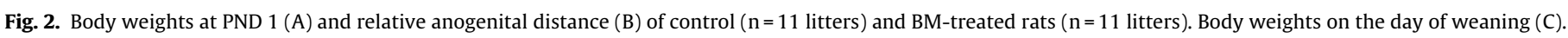
Age of complete preputial separation in control and BM-treated litters (D). Data are expressed as the mean \pm SEM. * indicates $p \leq 0.05$ (Student's $t$-test). 


\section{PND45}
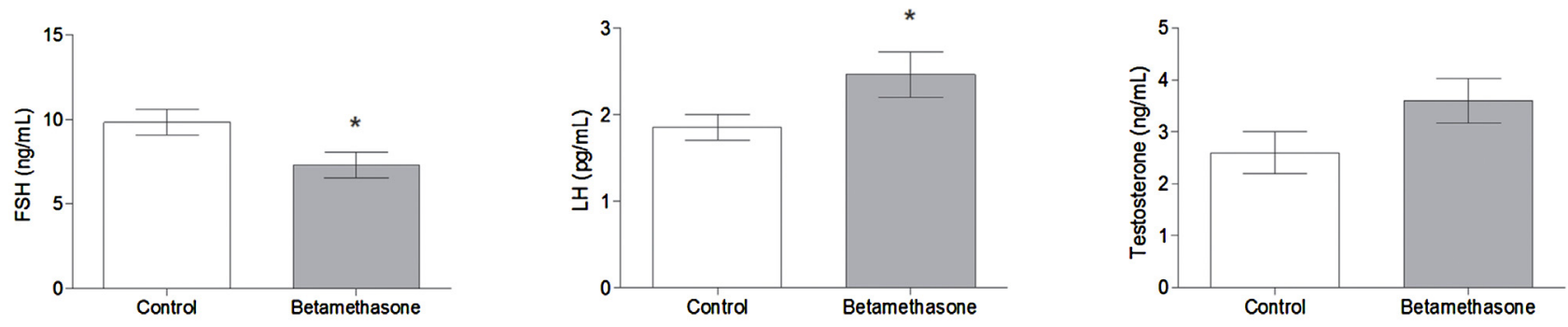

\section{PND110}
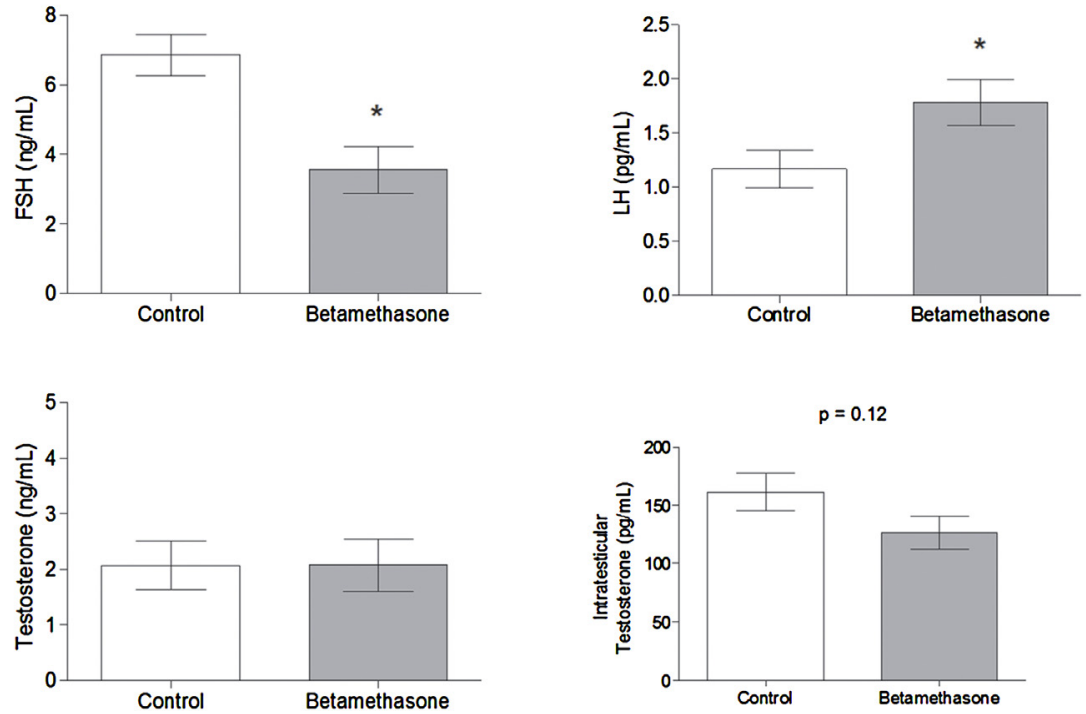

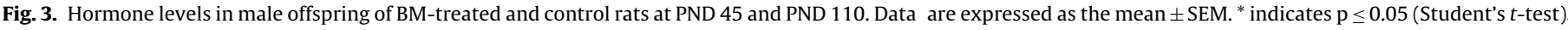

and male sex ratio (control: $0.41 \pm 0.04$ and BM: $0.50 \pm 0.05$ ) were similar. However, in the F2 male offspring, body weight was significantly reduced in the BM-group (Fig. 2A) without any changes in relative anogenital distance (Fig. 2B). At PND 21, the differences in body weights between experimental groups were maintained (Fig. 2C).

In the BM-group, there was a significant delay in the onset of puberty as determined by preputial separation (Fig. 2D). Circulating levels of FSH were significantly lower while LH levels were significantly higher at both ages (PND 45 and PND 110). Serum testosterone levels were unaltered (Fig. 3). Interestingly, ITT ratios were lower, although these were not statistically significant (Fig. 3).

Testicular weights were significantly higher in the BM-group while seminal vesicle weights were significantly lower at PND 45; however at PND 110 both organ weights were similar between groups (Table 1 ).

There were no alterations in histopathologic and morphometric analysis of the testis between the control and BM-treated group (Table 2); however, Leydig cell volume and function, according to the ITT ratio, were significantly decreased in BM-treated group at PND 110 (Fig. 4). Immunostaining for Cx43 and PCNA in the testis was also similar between groups (data not shown).

In the BM-treated group, there was a significant decrease in daily sperm production and the number of sperm in the caput/corpus and cauda epididymidis (Table 3 ). The percentage of both immobile sperm (Fig. 5) and morphologically abnormal sperm were significantly increased. Most of the abnormalities in the sperm were due to alterations in sperm heads (Table 4).The sperm samples from the BM-treated group showed an increase percentage of DNA damage (tail intensity), when compared with the control group (Fig. 6).

Fertility potential, after in utero artificial insemination, was significantly reduced in the BM-group and, consequently, preimplantation loss was significantly increased (Table 5).

\subsection{Study 2: sexual behavior and natural mating}

Sexual behavior was altered in the F2 BM-treated group, which displayed a significant delay prior to the first mount (Table 6). Few of these animals ejaculated in the females (approximately 9\%) during sexual intercourse. In contrast, the control animals showed an ejaculation frequency of almost 55\% (Table 6). Furthermore, the weight of the ejaculatory plugs obtained after the end of the mating period was reduced by approximately $31 \%$ in the BM-treated group as compared to controls.

After natural mating, the fertility potential was reduced and preimplantation loss significantly increased in the BM-treated group (Table 7). These results are similar to those observed after in utero artificial insemination (Table 5).

\subsection{Study 3: contractility of isolated seminal vesicles}

As shown in Fig. 7A, the potency of NE (adrenergic agonist) in inducing contractions in the isolated seminal vesicle was comparable between groups (control group: $\mathrm{pEC} 50=5.75 \pm 0.07$; $\mathrm{BM}$ group: pEC50 $=5.68 \pm 0.19$ ). However, the maximal tension devel- 
Table 1

Reproductive organ weights.

\begin{tabular}{|c|c|c|c|c|}
\hline \multirow[t]{2}{*}{ Parameters } & \multicolumn{2}{|l|}{ PND 45} & \multicolumn{2}{|l|}{ PND 110} \\
\hline & Control $(n=10)$ & Betamethasone $(n=10)$ & Control $(n=10)$ & Betamethasone $(n=10)$ \\
\hline Final body weight (g) & $216.20 \pm 3.27$ & $214.10 \pm 4.20$ & $385.20 \pm 7.20$ & $364.50 \pm 12.06$ \\
\hline \multicolumn{5}{|l|}{ Organ weights } \\
\hline Testis (g) & $1.13 \pm 0.02$ & $1.17 \pm 0.02$ & $1.78 \pm 0.03$ & $1.71 \pm 0.03$ \\
\hline Ventral prostate (mg) & $99.44 \pm 4.42$ & $96.07 \pm 5.40$ & $281.50 \pm 13.63$ & $253.30 \pm 16.52$ \\
\hline Seminal vesicle with secretion (mg) & $132.70 \pm 9.39$ & $108.80 \pm 5.85^{*}$ & $710.40 \pm 26.61$ & $688.60 \pm 34.46$ \\
\hline Seminal vesicle without secretion (mg) & - & - & $300.60 \pm 11.30$ & $311.60 \pm 11.68$ \\
\hline \multicolumn{5}{|l|}{ Relative organ weights } \\
\hline Testis (mg/100 g) & $521.10 \pm 8.59$ & $546.60 \pm 8.27^{*}$ & $0.46 \pm 0.01$ & $0.47 \pm 0.01$ \\
\hline Ventral prostate $(\mathrm{mg} / 100 \mathrm{~g})$ & $45.94 \pm 1.74$ & $44.98 \pm 2.61$ & $72.92 \pm 2.75$ & $69.24 \pm 3.82$ \\
\hline Seminal vesicle with secretion $(\mathrm{mg} / 100 \mathrm{~g})$ & $62.22 \pm 3.69$ & $51.57 \pm 3.28^{*}$ & $184.60 \pm 6.46$ & $189.10 \pm 8.17$ \\
\hline Seminal vesicle without secretion $(\mathrm{mg} / 100 \mathrm{~g}$ ) & - & - & $78.05 \pm 2.05$ & $86.46 \pm 5.61$ \\
\hline
\end{tabular}

Data expressed as the mean \pm SEM.

${ }^{*} \mathrm{p}<0.05$. (Student's $t$-test).

Table 2

Histological and morphometric assays ( $n=5$ /group).

\begin{tabular}{|c|c|c|}
\hline Parameter & Control & Betamethasone \\
\hline${ }^{a}$ Normal tubules at PND45 (\%) & $89.00(84.00-94.50)$ & $87.0(80.00-89.50)$ \\
\hline${ }^{a}$ Normal tubules at PND110 (\%) & $88.00(87.00-92.50)$ & $84.0(77.00-88.50)$ \\
\hline${ }^{\mathrm{b}}$ Category of cell maturation $(1-5)$ & $3.30(3.16-3.39)$ & $3.14(2.83-3.29)$ \\
\hline \multicolumn{3}{|l|}{ b Spermatogenesis dynamics } \\
\hline $\mathrm{I}-\mathrm{VI}(\%)$ & $28.00(28.00-98.50)$ & $33.00(27.50-35.00)$ \\
\hline VII-VIII (\%) & $32.00(27.00-35.50)$ & $30.00(24.50-35.50)$ \\
\hline IX-XIII (\%) & $29.00(28.50-30.50)$ & $30.00(27.50-31.50)$ \\
\hline $\mathrm{XIV}(\%)$ & $8.00(5.50-8.00)$ & $8.00(7.00-11.00)$ \\
\hline${ }^{\mathrm{b}}$ Tubule diameter PND45 ( $\left.\mu \mathrm{m}\right)$ & $257.80 \pm 2.78$ & $257.10 \pm 4.37$ \\
\hline${ }^{\mathrm{b}}$ Epithelial cell height at PND45 $(\mu \mathrm{m})$ & $76.98 \pm 1.89$ & $79.57 \pm 0.83$ \\
\hline${ }^{\mathrm{b}}$ Tubule diameter at PND110 $(\mu \mathrm{m})$ & $258.30 \pm 3.38$ & $250.00 \pm 5.19$ \\
\hline${ }^{\mathrm{b}}$ Epithelial cell height at PND110 $(\mu \mathrm{m})$ & $86.96 \pm 1.70$ & $82.98 \pm 1.77$ \\
\hline${ }^{a}$ Sertoli cell number at PND110 & $18.45 \pm 0.82$ & $18.36 \pm 0.50$ \\
\hline
\end{tabular}

"p<0.05. (Student's $t$-test).

a Data are expressed as the median and interquartile intervals (Mann-Whitney test).

b Data are expressed as the mean \pm SEM.
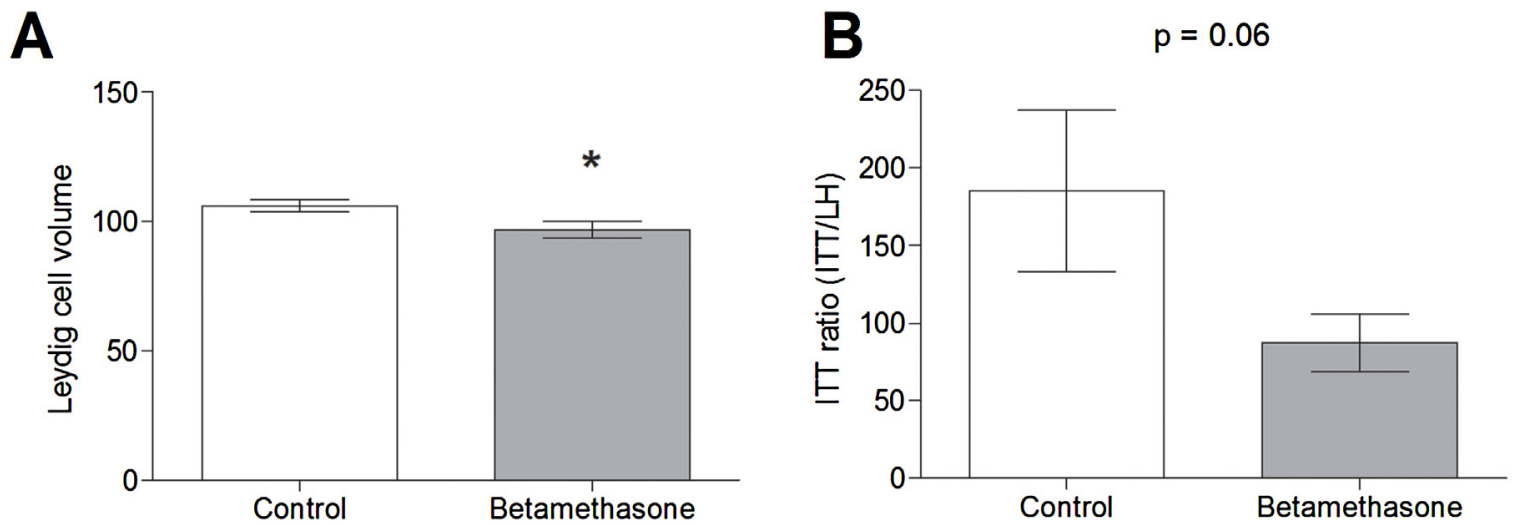

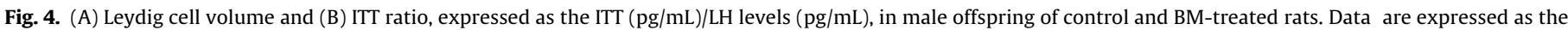
mean \pm SEM. * indicates $\mathrm{p} \leq 0.05$. (Student's $t$-test).
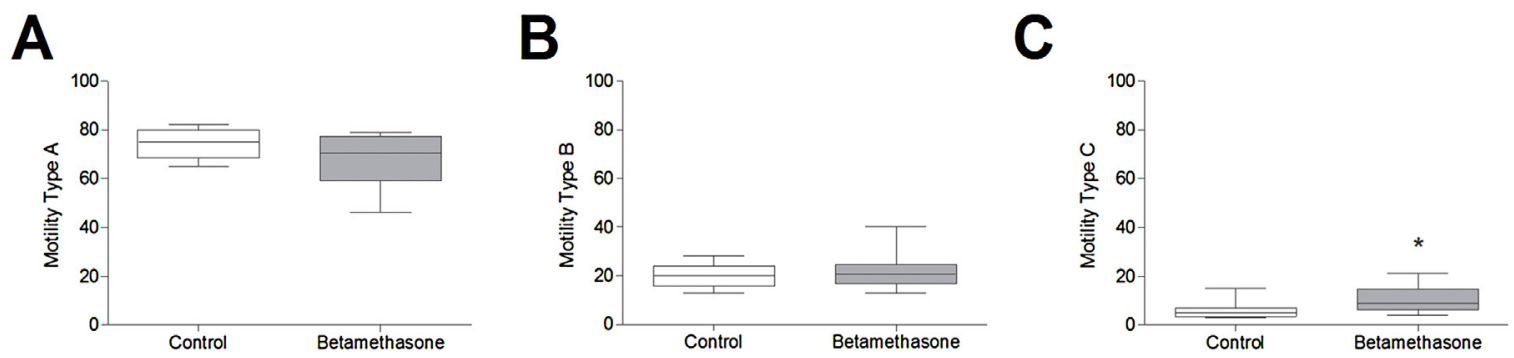

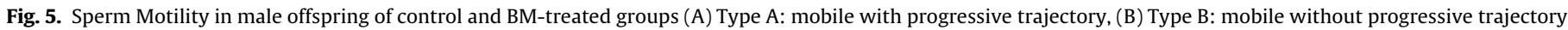
and (C) Type C: immobile. Data are expressed as median and interquartile intervals. * indicates $\mathrm{p} \leq 0.05$. (Mann-Whitney test). 
Table 3

Sperm counts and sperm epididymal transit time at PND110.

\begin{tabular}{|c|c|c|}
\hline Parameter & Control $(n=10)$ & Betamethasone $(n=10)$ \\
\hline $\begin{array}{l}\text { Sperm count in the testis } \\
\text { Spermatid Number }\left(\times 10^{6} / \text { testis }\right) \\
\text { Relative Spermatid Number }\left(\times 10^{6} / \mathrm{g} / \text { testis }\right) \\
\text { Daily Sperm Production }\left(\times 10^{6} / \text { testis/day }\right) \\
\text { Relative Daily Sperm Production }\left(\times 10^{6} / \text { testis/g/day }\right)\end{array}$ & $\begin{array}{l}239.00 \pm 6.72 \\
164.20 \pm 4.84 \\
39.18 \pm 1.10 \\
26.76 \pm 0.82\end{array}$ & $\begin{array}{l}210.90 \pm 11.65^{*} \\
152.20 \pm 6.58 \\
34.58 \pm 1.91^{*} \\
24.95 \pm 1.08\end{array}$ \\
\hline $\begin{array}{l}\text { Epididymal Sperm Count } \\
\text { Sperm number in caput/corpus }\left(\times 10^{6} / \text { organ }\right) \\
\text { Sperm number in cauda }\left(\times 10^{6} / \text { organ }\right) \\
\text { Sperm transit time in caput/corpus (days) } \\
\text { Sperm transit time in cauda (days) }\end{array}$ & $\begin{array}{l}158.10 \pm 4.49 \\
231.40 \pm 5.72 \\
4.02 \pm 0.21 \\
5.95 \pm 0.21\end{array}$ & $\begin{array}{l}130.50 \pm 8.29^{*} \\
204.30 \pm 12.32^{*} \\
3.83 \pm 0.26 \\
5.96 \pm 0.31\end{array}$ \\
\hline
\end{tabular}

Data are expressed as the mean \pm SEM.

$\mathrm{p}<0.05$ (Student's $t$-test).

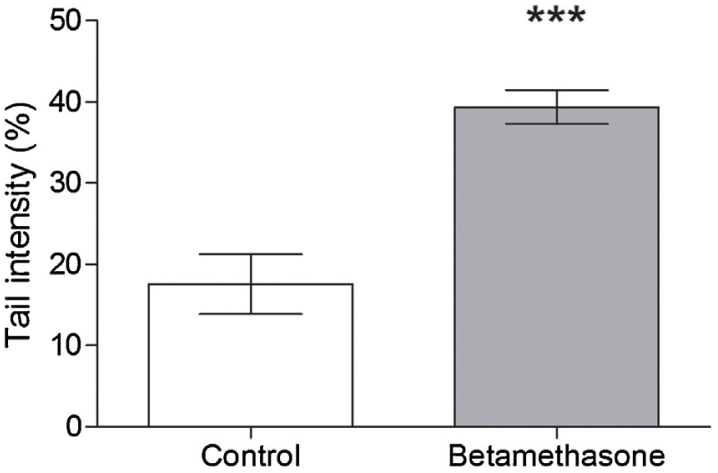

Fig. 6. Sperm DNA fragmentation in male offspring of control and BM groups observed by percentage of tail intensity ${ }^{* * *}$ indicates $\mathrm{p} \leq 0.001$. (Mann-Whitney test).

Table 4

Analysis of sperm morphology at PND110.

\begin{tabular}{lll}
\hline Parameters & Control $(\mathrm{n}=10)$ & Betamethasone $(\mathrm{n}=10)$ \\
\hline Normal sperm (\%) & $97.50(96.25-99.00)$ & $94.00(90.00-96.25)^{*}$ \\
Abnormal sperm (\%) & & \\
Isolated head & $2.00(0.62-2.50)$ & $3.50(2.00-6.25)^{*}$ \\
Broken tail & $0.50(0.00-1.00)$ & $1.00(0.50-1.50)$ \\
Cytoplasmic droplet (\%) & $25.00(20.75-26.25)$ & $26.50(20.50-30.25)$ \\
\hline
\end{tabular}

Data are expressed as the median and interquartile intervals.

p $<0.05$ (Mann-Whitney test).

Table 5

Fertility assays following in utero artificial insemination at PND110.

\begin{tabular}{lll}
\hline Parameter & Control $(\mathrm{n}=10)$ & $\begin{array}{l}\text { Betamethasone } \\
(\mathrm{n}=10)\end{array}$ \\
\hline a Pregnancy rate (\%) & 50.00 & 90.00 \\
${ }^{\text {a }}$ Fertility potential (\%) & 75.00 & $53.33^{*}$ \\
${ }^{a}$ Pre- implantation loss (\%) & 25.00 & $46.67^{*}$ \\
a Post- implantation loss (\%) & 40.00 & 25.00 \\
${ }^{b}$ Body weight of the dams (g) & $298.80 \pm 10.82$ & $308.50 \pm 6.56$ \\
b Uterus weight with fetuses (g) & $8.55 \pm 1.29$ & $8.42 \pm 1.39$ \\
b Corpora lutea number & $11.80 \pm 1.11$ & $13.89 \pm 0.54$ \\
b Implantation number & $9.60 \pm 1.89$ & $7.22 \pm 1.05$ \\
b Reabsorption number & $2.60 \pm 0.68$ & $1.78 \pm 0.49$ \\
b Fetus weight (mg) & $310.00 \pm 16.43$ & $333.80 \pm 23.45$ \\
b Placental weight (mg) & $270.00 \pm 8.37$ & $277.50 \pm 31.15$ \\
\hline
\end{tabular}

oped (Emax) for NE in the BM-treated group was significantly decreased as compared to controls (Fig. 7B). The same pattern was observed for CCh (Fig. 6C and D), a cholinergic agonist (control group: pEC50 $=4.79 \pm 0.09$; BM group: $\mathrm{pEC} 50=4.80 \pm 0.16$ ).

\section{Discussion}

Betamethasone is one of the most prescribed compounds for promoting fetal development at critical periods of intrauterine development, and is known to cause permanent physiological alterations [24,25]. Several studies have demonstrated the impact of intrauterine BM-treatment during long-term development, with emphasis on neuronal, endocrine, renal and reproductive problems [3,7-10,26,27].

Indeed, in recent years, several studies have reported on the impact of prenatal glucocorticoid treatment not only on the exposed offspring, but also on subsequent generations, resulting in altered protein expression, growth factors, and hypothalamicpituitary-adrenal axis [6,11-13]. The present study indicates that prenatal BM exposure during critical periods of male fetal sexual development can induce alterations in the reproductive system of the second generation males, and that this impact can be observed from birth to adulthood.

Birth weight reduction is an important target that may be correlated with fetal programming and can have lasting impacts over the life of the individual [28]. In the present study, we observed a reduction in the birth weight of F2 BM-treated group, which is similar to previous findings $[11,13]$. This reinforces the possible inter-generational impact of BM treatment. We previously observed a similar effect, in which male fetuses exposed to BM during intrauterine development displayed reduced weight [8]. Moreover, these fetuses displayed other alterations such as poor weight gain during early stages of postnatal development and delayed puberty onset [9,29-31].

Circulating levels of FSH were decreased in F2 rats at both ages, while LH levels were increased without alterations to serum testosterone levels. We previously observed a similar pattern of circulating hormone levels in rats treated in utero to $\mathrm{BM}[7,8]$. Interestingly, this effect is maintained in the second generation. Previous studies by Iqbal et al. [13] reported that BM altered the hypophyseal-pituitary-adrenal axis over two generations. The present observations suggest that a similar effect may be occurring in the hypophyseal-pituitary-testicular axis. This may, in part, explain the decreased levels of FSH. Lower levels of FSH can, in turn, be correlated with the decreased sperm production via its actions on spermatogenesis $[8,32]$.

While testosterone levels were unaltered by BM, serum LH levels were increased and the ITT ratio of Leydig cells was decreased. Since the Leydig cell volume was decreased, and this is generally correlated with lower testosterone production [33], the higher LH levels may reflect the need for a greater stimulation of the Leydig cells in order to maintain circulating levels of testosterone [15].

Changes in sexual behavior were observed in rats from the BM-treatment group. These rats displayed a significant decrease in sexual interest with respect to the time of first mount and 
Table 6

- Male sexual behavior at PND90.

\begin{tabular}{|c|c|c|}
\hline Parameters & Control $(n=11)$ & Betamethasone $(\mathrm{n}=11)$ \\
\hline${ }^{a}$ Latency to the first mount (s) & $92.00(56.00-104.00)(n=11)$ & $116.00(87.00-262.00)(n=11)$ \\
\hline${ }^{a}$ Number of mounts until the first ejaculation & $14.00(9.00-20.00)(n=11)$ & $10.00(6.00-14.00)(n=11)$ \\
\hline${ }^{\mathrm{a}}$ Latency to the first intromission (s) & $172.00(108.30-215.50)(n=10)$ & $173.50(127.00-383.30)(n=8)$ \\
\hline${ }^{a}$ Number of intromissions until the first ejaculation & $33.50(17.50-45.00)(n=10)$ & $27.50(12.00-50.00)(n=8)$ \\
\hline${ }^{\mathrm{b}}$ Frequency of ejaculations (\%) & 54.54 & $9.09^{*}$ \\
\hline${ }^{\mathrm{a}}$ Ejaculatory plugs (mg) & $248.50(190.00-281.00)(n=9)$ & $171.90(79.45-211.10)(\mathrm{n}=6)^{*}$ \\
\hline
\end{tabular}

a Values expressed as median and interquartile intervals (Mann-Whitney test).

b Values expressed as percentage (Chi-Square test).

* $\mathrm{p}<0.05$.

Table 7

Fertility assay after natural mating in animals at PND90.

\begin{tabular}{|c|c|c|}
\hline Parameters & Control $(n=9)$ & Betamethasone $(n=9)$ \\
\hline Pregnancy rate (\%) & 81.81 & 81.81 \\
\hline a Fertility potential (\%) & $100.00(91.77-100.00)$ & $87.50(59.60-100.00)^{*}$ \\
\hline a Pre- implantation loss (\%) & $0.00(0.00-8.33)$ & $12.50(0.00-40.00)^{*}$ \\
\hline a Post- implantation loss (\%) & $0.00(0.00-8.10)$ & $0.00(0.00-13.95)$ \\
\hline${ }^{\mathrm{b}}$ Body weight of dams (g) & $355.30 \pm 8.10$ & $344.50 \pm 10.99$ \\
\hline${ }^{\mathrm{b}}$ Uterus weight with fetuses ( $\mathrm{g}$ ) & $56.47 \pm 1.65$ & $53.03 \pm 6.22$ \\
\hline${ }^{\mathrm{b}}$ Corpora lutea number & $12.56 \pm 0.24$ & $13.78 \pm 0.78$ \\
\hline${ }^{\mathrm{b}}$ Implantation number & $12.11 \pm 0.35$ & $10.78 \pm 1.46$ \\
\hline${ }^{\mathrm{b}}$ Reabsorption number & $0.44 \pm 0.24$ & $0.67 \pm 0.29$ \\
\hline${ }^{\mathrm{b}}$ Fetus weight (g) & $2.87 \pm 0.06$ & $2.83 \pm 0.06$ \\
\hline b Placental weight (g) & $0.49 \pm 0.01$ & $0.55 \pm 0.06$ \\
\hline
\end{tabular}

a Values expressed as median and interquartile intervals (Mann-Whitney test).

b Values expressed as mean \pm SEM (Student's $t$-test).

$\mathrm{p}<0.05$.

A

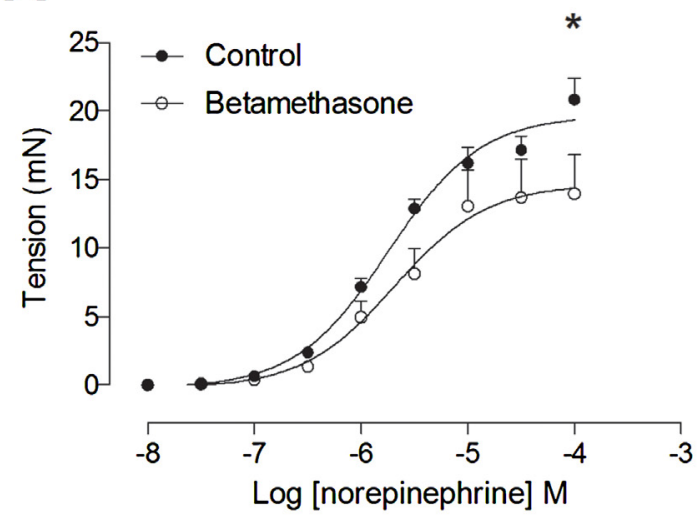

C

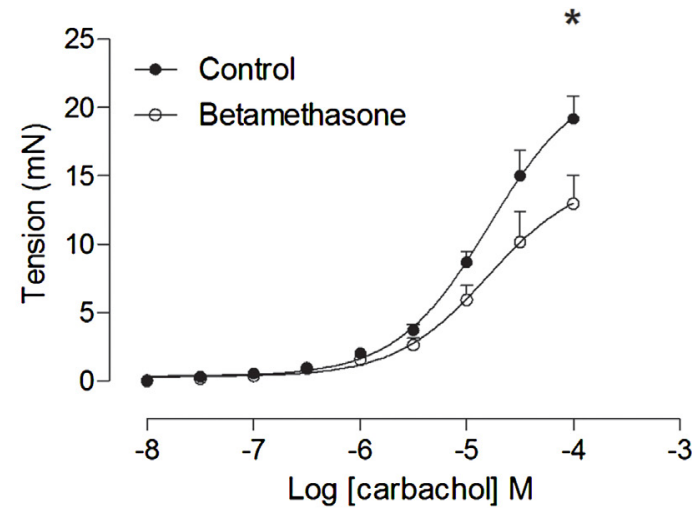

B

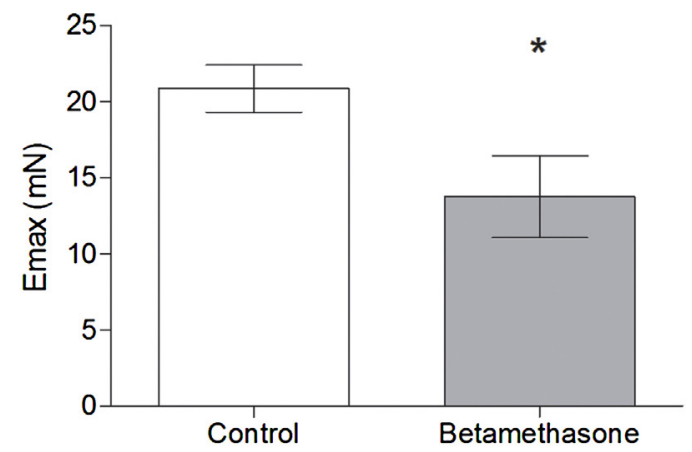

D

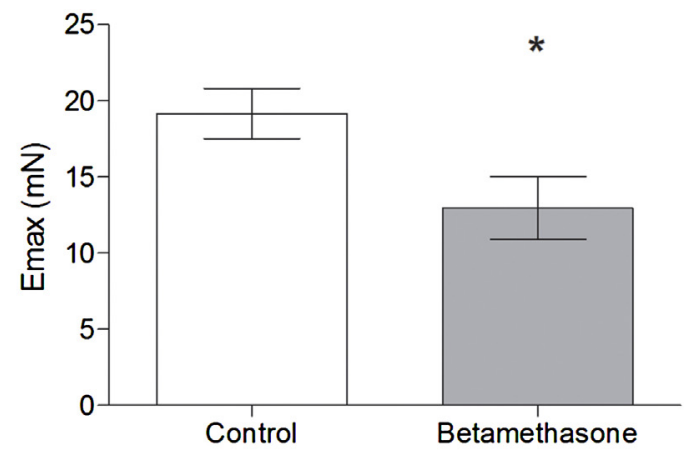

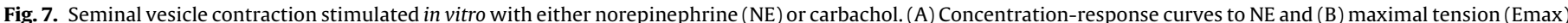

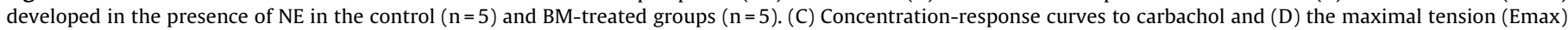
developed in the presence of carbachol in the control $(n=5)$ and BM-treated groups $(n=5)$. Data are expressed as the mean \pm SEM. * indicates $p \leq 0.05$ (Student's $t$-test). 
decreased number of ejaculations, in which only $9 \%$ of the animals were able to ejaculate. Disruption of male sexual behavior has been described after prenatal exposure to stress or to several compounds, such as glucocorticoids, that alter fetal programming, $[9,34,35]$. Male sexual behavior in adult mammals is modulated by testosterone; however, this hormone is not the only factor that regulates sexual performance, which also requires normal function of the hypothalamic-pituitary-testicular axis and neuronal control [35]. Pereira et al. [34] demonstrated that after testosterone replacement, male rats continue to exhibit sexual behavior dysfunction, suggesting that other factors contribute to the impairment of sexual interest. These may include hormonal imbalance, as suggested by the high levels of $\mathrm{LH}$, or changes in neurotransmitter responses in the sexual reproductive organs. Interestingly, in our previous study [8], the BM-treated group did not show alterations in sexual behavior. Hence, this effect may only manifest itself as an inter-generational effect.

During the emission phase of ejaculation, $70-90 \%$ of the ejaculate consists of seminal fluid from seminal vesicle (70-90\% of ejaculated), which is dependent on testosterone levels [36] and rhythmic contractions of smooth muscle induced by the sympathetic and parasympathetic nervous system [37]. Pereira and Arena [34] reported that intrauterine glucocorticoids reduce the contraction of seminal vesicles in adults, as observed in the present work. This may explain the reduced ejaculated plug weights also observed in BM-treated $\mathrm{F} 2$ rats.

Our data also indicates that the weight of the testis was significantly increased while seminal vesicle weights were decreased, but only at PND 45. Previously, in the F1 generation [8], we found the same pattern of weight results in both ages (puberty and adulthood). These findings could be explained, at least in part, due to a specific intergenerational BM effects on the reproductive organs. It is known that the sympathetic and parasympathetic innervations are important for the seminal vesicle contractility activity and fluid production, respectively [38,39]. Based on our pharmacological observations we hypothesize that the decrease in the seminal vesicle weight observed at puberty did not persist until adulthood due to a possible effect of BM on these innervations, leading to a possible decrease in gland secretion production and elimination. In other words, at adulthood the seminal vesicle of the BM group may be producing and releasing less secretion than the control group, leading to comparable organ weights.

Fertility tests performed on the same animals as those used for sexual behavior showed a significant reduction in fertility potential [40]. However, the decreased ability to ejaculate and the reduced ejaculated plug weights observed in the F2 BM-treated animals could have interfered with the interpretation of fertility results, and have directly resulted in reduction of fertility potential. To circumvent this, in utero artificial insemination was performed [40-43]. The results indicated that artificial insemination still resulted in decreased fertility potential in the second generation BM-treated rats, thereby suggesting that the actual quality of the semen, or gametes, was greatly reduced in these animals.

To further examine the quality of semen samples in BM-treated F2 animals, sperm morphology, motility and sperm DNA damage were analyzed [40,44-46]. Considering that both motility and morphology are important for assessing sperm quality and can be directly correlated to sperm fertile capacity [47], our data indicate that the reduction on sperm fertility in the second generation of BM-treated rats is due to, in part, to a reduction in motility as well as an increase in sperm morphological defects.

Comet assays indicated an increase in the percentage of DNA damage in the BM-treated group. Since sperm DNA damage may be related to an increase in premature embryo losses as reflected by pre-implantation and/or initial post-implantation loss [48], these results might explain the increased pre-implantation loss observed in the BM-treated group. These data, along with the fertility assays, support the notion that semen quality was seriously compromised and maintained over two generations in BM-treated rats.

In conclusion, prenatal betamethasone exposure leads to intergenerational long-term reproductive impairment in male rats and these findings raise concern for humans, considering the use of BM in pregnant women.

\section{Conflict of interest statement}

The authors declare that there are no conflicts of interest.

\section{Acknowledgements}

We are grateful for the financial support of FAPESP - The State of São Paulo Research Foundation [Grant number 2012/25350-1]; CNPq - National Council for Scientific and Technological Development [Grant number 308842/2013-8]; FQRNT - The Fonds de recherche du Québec - Nature et technologies and The Natural Sciences Research Council of Canada [Grant number 155065-06]. Furthermore, we wish to acknowledge Dr. Janete Anselmo-Franci and to Ruither de Oliveira Gomes Carolino of the Department of Morphology, Stomatology and Physiology, Dental School of Ribeirão Preto, University of São Paulo - USP, for the collaboration with the hormonal assays, and Julie Dufresne of INRS-Institut Armand-Frappier, for her assistance. José Eduardo Bozano, assisting academic support, of the Department of Morphology, Institute of Biosciences, São Paulo State University - UNESP, is also thanked for his assistance.

\section{References}

[1] M.N. Manojlović-Stojanoski, N. Nestorović, V. Milošević, Prenatal glucocorticoids: short-Term benefits and long-Term risks, in: X. Qian (Ed.), Glucocorticoids - New Recognition of Our Familiar Friend (2012).

[2] A.H. Jobe, R.F. Soll, Choice and dose of corticosteroid for antenatal treatments, Am. J. Obstet. Gynecol. 190 (4) (2004) 878-881.

[3] E. de Souza, S. Kobayashi, M. de J. Simões, L. Camano, L. Kulay Júnior, Ação da Betametasona em Ratas Prenhes: Impacto sobre os Níveis de Corticosterona e Glândulas Adrenais Maternas e Fetais, Revista Brasileira de Ginecologia e Obstetrícia 23 (10) (2001) 667-673.

[4] A.L. Fowden, A.J. Forhead, Endocrine mechanisms of intrauterine programming, Reproduction 127 (5) (2004) 515-526.

[5] V.G. Moisiadis, S.G. Matthews, Glucocorticoids and fetal programming part 1: outcomes, Nat. Rev. Endocrinol. 10 (7) (2014) 391-402.

[6] A. Crudo, S. Petropoulos, V.G. Moisiadis, M. Iqbal, A. Kostaki, Z. Machnes, M. Szyf, S.G. Matthews, Prenatal synthetic glucocorticoid treatment changes DNA methylation states in male organ systems: multigenerational effects, Endocrinology 153 (7) (2012) 3269-3283.

[7] C.S. Borges, A.F. Dias, J.L. Rosa, P.V. Silva, R.F. Silva, A.L. Barros, M. Sanabria, M.T. Guerra, M. Gregory, D.G. Cyr, G.K.W. De, Alterations in male rats following in utero exposure to betamethasone suggests changes in reproductive programming, Reprod. Toxicol. 63 (2016) 125-134.

[8] C.D. Borges, A.F. Dias, P.V. Silva, J.L. Rosa, M.T. Guerra, R.F. Silva, L.R. Kiguti, A.S Pupo, W.G. Kempinas, Long-term adverse effects on reproductive function in male rats exposed prenatally to the glucocorticoid betamethasone, Toxicology 376 (2016) 15-22.

[9] R.C. Piffer, P.C. Garcia, D.C. Gerardin, W.G. Kempinas, O.C. Pereira, Semen parameters, fertility and testosterone levels in male rats exposed prenatally to betamethasone, Reprod. Fertil. Dev. 21 (5) (2009) 634-639.

[10] R.C. Piffer, P.C. Garcia, O.C. Pereira, Adult partner preference and sexual behavior of male rats exposed prenatally to betamethasone, Physiol. Behav $98(1-2)(2009)$ 163-167.

[11] A.J. Drake, L. Liu, D. Kerrigan, R.R. Meehan, J.R. Seckl, Multigenerationa] programming in the glucocorticoid programmed rat is associated with generation-specific and parent of origin effects, Epigenetics 6 (11) (2011) 1334-1343.

[12] A.J. Drake, B.R. Walker, J.R. Seckl, Intergenerational consequences of fetal programming by in utero exposure to glucocorticoids in rats, American journal of physiology, Regul. Integr. Comp. Physiol. 288 (1) (2005) R34-R38.

[13] M. Iqbal, V.G. Moisiadis, A. Kostaki, S.G. Matthews, Transgenerational effects of prenatal synthetic glucocorticoids on hypothalamic-pituitary-adrenal function, Endocrinology 153 (7) (2012) 3295-3307.

[14] R.M. Parker, Testing for reproductive toxicity, in: R.D. Hood (Ed.), Developmental and Reproductive Toxicology: A Practical Approach, CRC Press, 2006, pp. 472-474. 
[15] W.H. Chang, S.S. Li, M.H. Wu, H.A. Pan, C.C. Lee, Phthalates might interfere with testicular function by reducing testosterone and insulin-like factor 3 levels, Hum. Reprod. 30 (11) (2015) 2658-2670.

[16] R. Filler, Methods for evaluation of rats epididymal sperm morphology, in: J.H.H.R.E. Chapin (Ed.), Male Reproductive Toxicology, Academic Press, California, 1993, pp. 334-343.

[17] G.W. Robb, R.P. Amann, G.J. Killian, Daily sperm production and epididymal sperm reserves of pubertal and adult rats, J. Reprod. Fertil. 54 (1) (1978) 103-107.

[18] A.M. Codrington, B.F. Hales, B. Robaire, Spermiogenic germ cell phase-specific DNA damage following cyclophosphamide exposure, J. Androl. 25 (3) (2004) 354-362.

[19] G.L. Foley, Overview of male reproductive pathology, Toxicol. Pathol. 29 (1) (2001) 49-63.

[20] F.C. Toledo, J.E. Perobelli, F.P.C. Pedrosa, J.A. Anselmo-Franci, W.D.C. Kempinas, In utero protein restriction causes growth delay and alters sperm parameters in adult male rats, Reprod. Biol. Endocrinol. 9 (2011)

[21] Y. Clermont, S.C. Harvey, Duration of the cycle of the seminiferous epithelium of normal, hypophysectomized and hypophysectomized-hormone treated albino rats, Endocrinology 76 (1965) 80-89.

[22] C.A. Cury, R. Azoubel, F. Batigalia, Bladder drainage and glandular epithelia morphometry of the prostate in benign prostatic hyperplasia with severe symptoms, Int. Braz. J. Urol. 32 (2) (2006) 211-215.

[23] F.D. Nojimoto, R.C. Piffer, L.R. Kiguti, C. Lameu, A.C. de Camargo, O.C. Pereira, A.S. Pupo, Multiple effects of sibutramine on ejaculation and on vas deferens and seminal vesicle contractility, Toxicol. Appl. Pharmacol. 239 (3) (2009) $233-240$

[24] E. Zambrano, C. Guzman, G.L. Rodriguez-Gonzalez, M. Durand-Carbajal, P.W. Nathanielsz, Fetal programming of sexual development and reproductive function, Mol. Cell. Endocrinol. 382 (1) (2014) 538-549.

[25] C. Rabadan-Diehl, P. Nathanielsz, From Mice to Men: research models of developmental programming J. Dev. Orig. Health Dis. 4 (1) (2013) 3-9.

[26] R. Pascual, M. Valencia, S. Larrea, C. Bustamante, Single course of antenatal betamethasone produces delayed changes in morphology and calbindin-D28k expression in a rat's cerebellar Purkinje cells, Acta Neurobiol. Exp. (Wars.) 74 (4) (2014) 415-423

[27] Y. Su, J. Bi, V.M. Pulgar, J. Figueroa, M. Chappell, J.C. Rose, Antenatal glucocorticoid treatment alters $\mathrm{Na}+$ uptake in renal proximal tubule cells from adult offspring in a sex-specific manner, Am. J. Physiol. Renal Physiol. 308 (11) (2015) F1268-75.

[28] M.A. Hanson, P.D. Gluckman, Developmental origins of health and disease: new insights, Basic Clin. Pharmacol. Toxicol. 102 (2) (2008) 90-93.

[29] D.J. Barker, K.L. Thornburg, Placental programming of chronic diseases, cancer and lifespan: a review, Placenta 34 (10) (2013) 841-845.

[30] S. Melching-Kollmuss, K.C. Fussell, R. Buesen, M. Dammann, S. Schneider, H. Tennekes, B. van Ravenzwaay, Anti-androgenicity can only be evaluated using a weight of evidence approach, Regul. Toxicol. Pharm. 68 (1) (2014) 175-192.

[31] D.J. Barker, In utero programming of chronic disease, Clin. Sci. (Lond.) 95 (2) (1998) 115-128

[32] P.J. O'Shaughnessy, Hormonal control of germ cell development and spermatogenesis, Semin. Cell Dev. Biol. 29 (2014) 55-65.
[33] B.R. Zirkin, H. Chen, Regulation of Leydig cell steroidogenic function during aging, Biol. Reprod. 63 (4) (2000) 977-981.

[34] O.C.M. Pereira, A.C. Arena, F. Yasuhara, W.G. Kempinas, Effects of prenatal hydrocortisone acetate exposure on fertility and sexual behavior in male rats, Regul. Toxicol. Pharm. 38 (1) (2003) 36-42

[35] D.C. Gerardin, O.C. Pereira, W.G. Kempinas, J.C. Florio, E.G. Moreira, M.M. Bernardi, Sexual behavior, neuroendocrine, and neurochemical aspects in male rats exposed prenatally to stress, Physiol. Behav. 84 (1) (2005) 97-104.

[36] A. Alwaal, B.N. Breyer, T.F. Lue, Normal male sexual function: emphasis on orgasm and ejaculation, Fertil. Steril. 104 (5) (2015) 1051-1060.

[37] F. Giuliano, P. Clement, Physiology of ejaculation: emphasis on serotonergic control, Eur. Urol. 48 (3) (2005) 408-417.

[38] J.N. Pennefather, W.A. Lau, F. Mitchelson, S. Ventura, The autonomic and sensory innervation of the smooth muscle of the prostate gland: a review of pharmacological and histological studies, J. Auton. Pharmacol. 20 (4) (2000) 193-206.

[39] B.P.B. Setchell, W.G. Anatomy, Vasculature, and innervation of the male reproductive tract, in: J.D. Neill (Ed.), Knobil \& Neill's Physiology of Reproduction, Elsevier, 2006, pp. 771-825.

[40] C.D. Fernandez, E.M. Porto, A.C. Arena, G. Kempinas Wde, Effects of altered epididymal sperm transit time on sperm quality, Int. J. Androl. 31 (4) (2008) 427-437.

[41] W.D.G. Kempinas, G.R. Klinefelter, The epididymis as a target for toxicants, Compr. Toxicol. (2014) 149-166.

[42] G.R. Klinefelter, Actions of toxicants on the structure and function of the epididymis, in: H.B. Robaire (Ed.), The Epididymis-From Molecules To Clinical Practice, Kluwer Academic/Plenum Publisher, New York, 2002, pp. 353-369.

[43] G.R. Klinefelter, J.W. Laskey, S.D. Perreault, J. Ferrell, S. Jeffay, J. Suarez, N. Roberts, The ethane dimethanesulfonate-induced decrease in the fertilizing ability of cauda epididymal sperm is independent of the testis, J. Androl. 15 (4) (1994) 318-327.

[44] C.S. Borges, G. Missassi, E.S. Pacini, L.R. Kiguti, M. Sanabria, R.F. Silva, T.P. Banzato, J.E. Perobelli, A.S. Pupo, W.G. Kempinas, Slimmer or fertile? Pharmacological mechanisms involved in reduced sperm quality and fertility in rats exposed to the anorexigen sibutramine, PLoS One 8 (6) (2013) e66091.

[45] T.G. Jenkins, K.I. Aston, J.M. Hotaling, M.B. Shamsi, L. Simon, D.T. Carrell, Teratozoospermia and asthenozoospermia are associated with specific epigenetic signatures, Andrology 4 (5) (2016) 843-849.

[46] T.B. Mendes, C.C. Paccola, F.M. de Oliveira Neves, J.N. Simas, A. da Costa Vaz, R.E. Cabral, V. Vendramini, S.M. Miraglia, Resveratrol improves reproductive parameters of adult rats varicocelized in peripuberty, Reproduction 152 (1) (2016) 23-35.

[47] I. Mangelsdorf, J. Buschmann, B. Orthen, Some aspects relating to the evaluation of the effects of chemicals on male fertility, Regul. Toxicol. Pharmacol. 37 (3) (2003) 356-369.

[48] L.T. Martins, P.C. Santos Neto, S. Gaudêncio Neto, F.K. Vieira, E.S. Ribeiro, A. Mezzalira, A.D. Vieira, Equine seminal plasma on preserving the viability of frozen-thawed ram sperm, Anim. Reprod. 10 (4) (2013) 697-703. 